Ciencia y Educación, Vol. 5, No. 3, septiembre-diciembre, 2021

ISSN (impreso): 2613-8794・ISSN (en línea): 2613-8808

DOI: https://doi.org/10.22206/cyed.2021.v5i3.pp39-59

\title{
Lectura y escritura como prácticas onlife: un estudio etnográfico digital entre universitarios
}

\author{
Reading and Writing as Onlife Practices: A Digital \\ Ethnography Study among Undergraduate Students
}

\author{
Luis Alberto Gutiérrez ${ }^{a}$

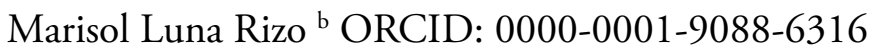 \\ Brenda Lorena González ${ }^{\mathrm{c}}$ ORCID: 0000-0001-9259-0893 \\ Recibido: 24/04/21 • Aprobado: 28/06/2021
}

Cómo citar: González Pérez, B. L., Luna Rizo, M., \& Gutiérrez, L. A. (2021). Lectura y escritura como prácticas onlife: un estudio etnográfico digital entre universitarios. Ciencia y Educación, 5(3), 39-59. Doi: https://doi.org/10.22206/cyed.2021.v5i3.pp39-59

\begin{abstract}
Resumen
Esta investigación tuvo como objetivo general identificar los factores que determinan las prácticas de lectura y escritura de diez estudiantes activos de la Universidad de Guadalajara observados por siete semanas con una metodología de etnografía digital que constó de cinco instrumentos. La pertinencia del estudio radica en que estas prácticas han sido atravesadas por la digitalidad en las últimas décadas, resignificando sus usos y consolidando la permanencia de los eventos letrados en gran parte de los actos cotidianos por medio de los dispositivos. Los resultados invitan a reflexionar sobre la complejidad de la lectura y escritura como prácticas onlife -un campo en el que lo virtual y lo presencial se encuentran constantemente entretejidos-, donde Internet se convierte en una herramienta de acceso a la lectura, lo que conlleva a la práctica de la multiliteracidad en la construcción de sentido, individual y colaborativo, por parte de los jóvenes.
\end{abstract}

Palabras clave: escritura, etnografía digital, redes sociales, medios electrónicos.

\begin{abstract}
This research focuses on identifying the factors that determine the reading and writing practices of ten University of Guadalajara undergraduate students during seven weeks, specifically in terms of their vernacular practices; digital ethnography methodology was employed through the use of five instruments. This study is pertinent since in recent decades these practices have been heavily influenced by digitality, re-signifying their uses and consolidating the permanence of literacy events in a large part of daily activities through devices. The results invite us to reflect on the complexity of reading and writing as onlife practices -a field in which the virtual and the face-to-face constantly come together-, where the Internet becomes a tool for access to reading, which leads to the practice of multiliteracies in the construction of individual and collaborative meaning in young people.
\end{abstract}

Keywords: Reading, writing, digital ethnography, social networks, electronic media.

\footnotetext{
a Universidad de Guadalajara, México. Correo-e: luis.gutierrez@academicos.udg.mx

b Universidad de Guadalajara, México. Correo-e: marisol.luna@cucea.udg.mx

c Universidad de Guadalajara, México. Correo-e: lorena.gonzalezp@cuaad.udg.mx
} 


\section{Introducción}

El proceso de consolidación de la Sociedad del Conocimiento en las dos primeras décadas del Siglo XXI y la evolución de diversas tecnologías en cada esfera de la vida humana han conformado escenarios contemporáneos en los que lo digital y lo no-digital convergen a cada segundo en actos cotidianos. Específicamente, en la investigación educativa este nivel de transformaciones tecnológicas ha derivado en la necesidad de contar con métodos aptos para indagar en objetos de estudio que cada vez son más multifacéticos, emergentes, flexibles y ubicuos. Este es el caso de la investigación de la lectura y la escritura, pues al ser prácticas socioculturales han evolucionado al mismo ritmo de su entorno.

Como menciona Rodríguez (2005), existen dos posturas principales en cuanto a la transformación de la lectura y la escritura derivadas de la emergencia e instauración de las Tecnologías de la Información y la Comunicación (TIC). Los conservadores aseguran que son actividades al borde de la desaparición, sobre todo en poblaciones juveniles. Los resultados del Módulo sobre la Lectura (MOLEC), que tiene como objetivo generar información estadística sobre el comportamiento lector de la población mexicana de 18 y más años de edad, parece dar evidencia de esto: en el año 2019 se encontró un descenso del 2\% de la población que lee algún material con respecto al año 2018 , así como casi un $10 \%$ menos comparado con los resultados del año 2015 (INEGI, 2019).

Por otra parte, de acuerdo a los tecnólogos es posible que tanto la lectura como la escritura solamente estén pasando por un proceso de adaptación a nuevas modalidades comunicativas. Visto así, gracias al desarrollo de las distintas TIC, este podría ser uno de los momentos históricos en los que más se lea y escriba de manera cotidiana. De acuerdo al Diagnóstico de Prácticas de Lectura en niños y jóvenes en México, realizado por IBBY México/A leer, se menciona que la lectura como práctica social está siendo atravesada por otras prácticas mediatizadas o digitalizadas, tal como la navegación en Internet y la lectura desde dispositivos electrónicos. Según este informe, la lectura en formato digital en México se concentra en poblaciones universitarias de entre 18 y 30 años y los contenidos más recurrentes son de tipo informativo-noticioso o bien contenidos cortos, mientras los libros de literatura son preferidos en formato impreso (Romero, 2016, p. 6). Esto sugiere que el soporte digital no se encuentra fagocitando al impreso, sino que ambos han encontrado vías de coexistencia en las prácticas de los usuarios.

Lo cierto es que más allá de estas posturas dicotómicas este escenario es una invitación a repensar las prácticas de lectura y escritura desde la complejidad de nuestro momento histórico. Así pues, el objetivo general de esta investigación fue identificar los factores que determinan las prácticas de lectura y escritura de los estudiantes de la Universidad de Guadalajara, específicamente las vernáculas.

La pertinencia de este estudio radica, de manera general, en la transformación que en las últimas décadas han tenido la lectura y la escritura al ser atravesadas por la digitalidad, ya que debido a esto las personas han resignificado sus usos, perpetuando y extendiendo su realización por medio de los dispositivos. De manera particular, dirigir esta investigación a la población universitaria respondió a que el reconocimiento de cómo leen y escriben, a través de cuáles medios, con cuáles propósitos y de qué manera lo socializan permita desarrollar estrategias de fomento acertadas a su contexto y sus necesidades.

A continuación, se expone la literacidad como un lente teórico óptimo para analizar la lectura y la escritura como prácticas situadas y de qué manera la evolución de los formatos las ha interpelado. A partir de estos datos se argumenta la selección metodológica de etnografía digital y se describen las cinco estrategias de recolección de datos que se implementaron en esta investigación en la que participaron 10 estudiantes de licenciatura de la Universidad de Guadalajara, en Jalisco, México: diario electrónico de eventos letrados, observación de redes sociales en línea, capturas de pantalla de conversaciones entorno a la lectura y la escritura, entrevistas semiestructuradas y grupos focales. Posteriormente, se exponen los principales resultados obtenidos. 


\section{De la lectura y la escritura a la literacidad: la evolución del concepto}

Desde la investigación de la cultura escrita, la lectura y la escritura han tenido varias fases que pueden ser entendidas solo a través de su contexto. En el siglo XX el análisis de la alfabetización se caracterizó por los enfoques lingüísticos o psicológicos (Cassany, 2005), pues se pasó de la cuantificación de analfabetas a la detección de las competencias de lectura y escritura que permitirían a los individuos la entrada al entorno laboral y productivo; es decir, los estudios de esa época se centraron en la alfabetización funcional (Riquelme \& Quintero, 2017). Ya hacia el siglo XXI la innovación tecnológica irrumpió en el panorama: de acuerdo a la Conferencia Mundial sobre la Ciencia, realizada en 1999, el saber científico dio lugar a innovaciones de beneficio para la humanidad (UNESCO,1999), pues los nuevos métodos de comunicación o el tratamiento de la información suscitaron oportunidades y tareas sin precedentes para el quehacer científico en general, pero específicamente para la significación de los alumnos ante el conocimiento.

Así, al iniciar el milenio, los artefactos y la circulación de los textos habían cambiado profundamente con la Revolución Digital. Emergieron nuevas habilidades relacionadas al análisis y el procesamiento crítico de la información, ambos aspectos relacionados al término literacidad, entendida como una competencia que trasciende el mero interés por la alfabetización funcional del siglo anterior. De acuerdo a la Organización de las Naciones Unidas para la Educación, la Ciencia y la Cultura:

La literacidad es un concepto que ha demostrado ser tanto complejo como dinámico, continuamente interpretado y definido en una multiplicidad de formas. La noción de las personas sobre el significado de ser alfabeto o analfabeto está influenciada por la investigación académica, agendas institucionales, el contexto nacional, valores culturales y experiencias personales (UNESCO, 2006, p.147).
Y en efecto, el concepto de literacidad ha presentado algunas transformaciones teórico-conceptuales que consideramos necesario mencionar para comprender su evolución:

- En primer lugar, Brian Street (1984) la consideró como una abreviatura de las prácticas sociales y las concepciones de lectura y escritura.

- Barton (2007) incluyó en el concepto todo tipo de sucesos cotidianos donde la palabra escrita tenga un papel, implicando que imágenes, películas, hipertextos e inclusive el arte pueden ser la base de un evento de literacidad.

- Lankshear \& Knobel (2008) la consideraron como una abreviatura de prácticas y concepciones sociales complejas de participación en la creación de significado, mediadas por textos y que se producen, reciben, distribuyen e intercambian también a través de la codificación digital.

- Por último, desde los Nuevos Estudios de Literacidad (NEL), el concepto refiere a una práctica crítica que se construye en interacciones cotidianas en contextos locales. Estos estudios emergen como contraparte de los enfoques psicolingüísticos y proponen el sociocultural, caracterizándose por abordar la lectura y la escritura como prácticas sociales situadas, socio-históricamente delimitadas, que pueden ser comprendidas únicamente en relación con el contexto en el que los usuarios las llevan a cabo (Cassany, 2005).

De hecho, de acuerdo a Leu y sus colaboradores (2013) la literacidad puede considerarse como un concepto deíctico, ya que su significado cambia de acuerdo al contexto en el que se practica. Así, es de esperarse que la evolución tecnológica de los medios comunicativos mantenga en constante cambio lo que significa que un individuo tenga o no la competencia de la literacidad, aún más si se tiene en cuenta lo señalado por el historiador de la cultura escrita Roger Chartier (2018), en tanto que esta es la primera vez que una sola revolución representa una metamorfosis en la técnica de la reproducción de los contenidos, la materialidad de los soportes de lectura y escritura, y la relación con lo escrito... todo al mismo tiempo. 


\section{La práctica de la lectura y la escritura: la evolución de los formatos}

Como argumentamos anteriormente, son evidentes algunas mutaciones de la cultura letrada en coyuntura con la Revolución Digital. Según recupera Roger Chartier, pueden sintetizarse en cuatro: 1) la influencia de la editorialización de la web en una lectura de tipo fragmentaria, menos profunda pero más amplia, 2) la emergencia de nuevos canales de socialización de lectura, como los blogs o las redes sociales, 3) la gestión de archivos desde una variedad de dispositivos, debido al cloud computing, manteniendo una lectura conectada, y 4) la transformación de la industria del libro por la economía digital global, que desarrolla ofertas multicanal y multisoporte para la lectura (Cordón \& Jarvio, 2015). Estos cambios en la dimensión cultural dan cuenta de cómo la digitalización ha tenido injerencia en nuestras maneras de pensar, actuar y significar la lectura y la escritura en la actualidad.

A estos hallazgos se suman las transformaciones a nivel cognitivo derivadas de la evolución de los formatos. Coiro (2003) ha indagado sobre la comprensión lectora en formatos digitales y señala la existencia de un corpus completo de habilidades que ponen en marcha procesos de pensamiento específicos para la construcción de significado cuando se trata de la lectura en red. Algunas de estas habilidades implican el razonamiento deductivo al dar clic en un enlace que acerque al usuario con el conocimiento buscado, el análisis crítico de la fiabilidad de la información presentada en la pantalla, o la interpretación constante de representaciones multimedia (imágenes, videos y sonidos), a la par del texto, para hacer sentido de la información (Coiro, 2003), lo cual enfatiza aún más en la importancia de la literacidad visual en entornos hiperconectados e interactivos (Gomes-Franco-e-Silva, 2019).

Ya sea en el plano cultural o cognitivo, es de alta importancia tener presente que la apropiación tecnológica es adquirida por medio de la práctica. En cuanto a la población juvenil, existen evidencias de que la experiencia de la lectura y la escritura comienza a diversificarse a través de los medios digitales. Por ejemplo, la contemporaneidad de la lectoescritura en la red irrumpe la intimidad o privacidad de la práctica que fue característica de los soportes impresos, transitando ahora por nodos públicos cotidianos con gran celeridad y profusión, espacios en los que todos leen y escriben para todos, aunque sea en forma de materiales vagabundos que se distinguen por su efimeridad (Zafra, 2017). Además, la promoción y socialización de la lectura dejó de estar eclipsada por la escuela y las bibliotecas, pues la proliferación de los canales Booktubers representa una nueva práctica de mediación lectora caracterizada por una socialización horizontal, siendo los mismos jóvenes quienes producen, difunden y consumen material audiovisual de análisis, colección y selección de lecturas, con la desventaja de que esa dinámica transite más por la motivación que por la reflexión profunda (Paladines-Paredes \& Margallo, 2020).

Ahora bien, las redes sociales en línea -en tanto industrias del yo-, revelan la importancia del ser visto/ leído como la condición sine qua non de la existencia virtual (Zafra, 2017). De acuerdo a Vargas (2018), Facebook ha emergido como un espacio intensivo para la lectura y la escritura como prácticas vernáculas. Las redes sociales en línea como Facebook, Twitter o Instagram representan escenarios donde las narrativas surgen a cada segundo e interpelan constantemente a los individuos. Es decir, constituyen espacios en los que los usuarios dan cuenta de sí mismos y de su identidad a través de sus prácticas de literacidad.

Ciertamente el ser humano en tanto un ser histórico y social ha tenido propensión por las narrativas, pero es hasta este momento en que la evolución de las TIC hace posible verlas y estudiarlas de una manera tan cronológica, personalizada y gráfica por medio de las biografías de las redes sociales en línea. En estos espacios la lectura y la escritura digital son prácticas obligadas para sus usuarios, pero, como argumentamos, crecientemente se entrelazan con recursos que a su vez involucran otro tipo de lecturas como imágenes, videos o emoticones, así como con habilidades que van por encima de la alfabetización funcional, como la digital o la literacidad crítica. 
En México, el estudio de DataReportal del 2020 -año de la investigación- muestra el uso de Internet por parte de su población: 89 millones, los mexicanos de 16 a 64 años son usuarios activos de redes sociales, lo que representa un $69 \%$ del total de la población del país. Además, de las 8 horas y 21 minutos diarios que en promedio estos usuarios navegan en Internet, 3 horas y 25 minutos son los que se dedican a las redes sociales (DataReportal, 2020). Específicamente, por parte de los universitarios mexicanos los tres principales usos de Internet están relacionados con actividades escolares o laborales, convivir en redes sociales y chatear (A leer/IBBY México-Banamex, 2015); tres actividades que involucran directamente las prácticas de lectura y escritura reunidas en un mismo espacio -virtual-, ubicuo, personal y portable por el acceso desde dispositivos móviles.

En síntesis, es ante esta complejidad de la lectura y la escritura contemporáneas que se considera que los NEL constituyen un enfoque sociocultural pertinente para analizar las prácticas vernáculas de lectura y escritura entre los universitarios y que, por su cotidianidad en la población juvenil, las redes sociales en línea brindan un campo de estudio fértil para analizarlos. El siguiente apartado argumenta la pertinencia del método etnográfico digital al estudiar la lectura y la escritura cuando estas se redefinen a través del paso por nuevos territorios que convergen entre lo tradicional y lo digital.

\section{De la etnografía clásica a la etnografía digital: la evolución de los métodos}

La etnografía tradicional tuvo su origen como método de la antropología social a principios del siglo pasado, tomando relevancia en el ámbito académico por los trabajos de Franz Boas, Bronislaw Malinowski, Alfred Radcliffe-Brown y Margaret Mead. Ellos, inspirados en ciencias naturales, como la zoología o la botánica, recolectaron información de manera directa al sumergirse en su campo de estudio y realizaron observaciones sistemáticas en el ambiente natural de culturas "primitivas" (Creswell, 2018).
Las condiciones adecuadas para el trabajo etnográfico fueron descritas por Malinowski en 1922 en uno de sus más célebres trabajos: Los Argonautas del Pacifico Occidental; estas se consideraron clave en las definiciones posteriores del método. John Creswell refiere que el método etnográfico es aquel "en el que el investigador estudia patrones compartidos de comportamientos, lenguaje y acciones de un grupo cultural intacto en un entorno natural durante un período prolongado de tiempo" (Creswell, 2014, p. 14). Por su parte, David M. Fetterman señala que "la etnografía da voz a las personas en su propio contexto local, generalmente basándose en citas literales y una descripción gruesa de los eventos. La historia se cuenta a través de los ojos de la gente local mientras persiguen su vida cotidiana en sus propias comunidades" (Fetterman, 2010, p. 1). Ambos concuerdan en la recuperación de la información como es vivida, pensada y significada por los sujetos.

Ahora bien, frente a otros métodos de investigación la etnografía presenta algunas singularidades. Por una parte, diversos autores (Hine, 2004; Briones, 1989; Rockwell, 2009; Barker, 1968) han señalado que el método etnográfico no requiere el planteamiento de hipótesis a priori, ya que llevar a campo este tipo de preconcepciones podría representar potencialmente un sesgo para observar e interpretar los fenómenos o sucesos de estudio. Otra característica más es que, como lo menciona Apud (2013), la etnografía puede presentar un carácter multitécnico, con lo cual no aplica discriminaciones y exclusiones que dicotomicen lo cualitativo de lo cuantitativo. Es decir, "la inclusión de técnicas cuantitativas en etnografía puede realizarse como formas complementarias de validación, cruzamiento y triangulación de datos, o como formas anidadas" (Apud, 2013, p. 221).

En cuanto a la validez del método, Goetz \& LeCompte (1988) afirman que cuenta con un alto grado de esta. Fundamentan su afirmación en que la etnografía requiere la observación y recogida de datos sostenida en el tiempo para hacer posible su análisis y comparación, así como en la posibilidad de ajustar y 
reajustar las categorías en el proceso de la investigación, de manera que logren dar cuenta de las experiencias como son vividas por los sujetos de estudio. Además, las técnicas utilizadas permiten corregir los sesgos que aparecen cuando el hecho es examinado por un solo observador.

No obstante, al pasar las décadas, la etnografía también tuvo un encuentro con lo digital. Como bien ha señalado Edgar Gómez-Cruz (2017), esto ha ocurrido en tanto que nuevos objetos de estudio han emergido, se han ampliado y complejizado campos de estudio y porque nuevas propuestas metodológicas han resultado de la sinergia de estos objetos y campos atravesados por la virtualidad.

A saber del lector, una de las propuestas metodológicas que ha cobrado fuerza en la última década para investigar en, por y desde la virtualidad ha sido la etnografía. Al comienzo de este milenio el libro Etnografía Virtual, de Christine Hine, constituyó el primer referente, al sentar la base para el estudio de los usos actuales del Internet. Podemos ver cómo el ánimo naturalista que inspiró el método etnográfico tradicional se sostiene aun cuando la tecnología entra en la ecuación:

La etnografía mantiene un interés especial por el estudio de "lo que la gente hace" con la tecnología $y$, una vez que interpretamos el ciberespacio como un lugar en el que se actúa, podemos empezar a estudiar exactamente qué se hace, por qué y en qué términos (Hine, 2004, p. 3).

En esa obra ella da un paso más al señalar que el agente de cambio en nuestras prácticas sociales no son las tecnologías en sí, sino cómo las hemos implementado y significado en nuestra vida cotidiana; eso es lo que transforma. De ahí la pertinencia del método etnográfico en los contextos virtuales, aunque no restrictivamente. Tanto Hine (2004) como Pink et al. (2019) concuerdan en que al implementar esta metodología se requieren diversas estrategias de observación para recuperar y entrelazar lo que sucede dentro y fuera de la virtualidad para contar con marcos interpretativos robustos.
Este mismo aspecto lo retoma Luciano Floridi (2015) cuando señala que nuestra era hiperconectada se ha caracterizado, entre otras cosas, por la difuminación de la frontera que dividía lo real y lo virtual, así como lo online de lo offline, ya que en los actos cotidianos los sujetos entremezclaban estas dimensiones. A su consideración, la re-ingeniería conceptual es uno de los temas más urgentes para que, con justicia semántica, podamos dar cuenta de nuestra contemporaneidad. Por eso comenzó por proponer el término onlife, para referirse a la manera de "estar" y "hacer" que ya no disocia lo que sucede dentro y fuera de línea.

Inclusive en la etnografía, esta redefinición del campo en que se realizan las prácticas llevó a que en los últimos ańos se afinara su conceptualización. El término "virtual" -como algo que pasa en potencia, pero no del todo- ha suscitado la suficiente controversia para dejar paso a su acepción como etnografía digital, pues "supera las críticas de la ausencia de materialidad de las prácticas sociales en Internet y teje una conexión con la perspectiva que de mejor manera da cuenta de la complejidad y la intersección de lo que sucede en línea y fuera de línea" (Bárcenas \& Preza, 2019, p. 135). Razones por las que a partir de este momento nos suscribimos a esta conceptualización.

Así, las diferencias entre la etnografía digital y la clásica parecen concentrarse en las posibilidades de los recursos abiertos que proporcionan los mundos virtuales y los dispositivos de acceso. En primer lugar, el etnógrafo ya no debe desplazarse al espacio físico de su población objetivo para realizar la observación. La inmersión al campo la puede realizar desde cualquier lugar mientras tenga acceso al ciberespacio, abriendo la posibilidad de abordar objetos de estudio multisituados. En segundo lugar, estas observaciones ya no son necesariamente síncronas, pues al observar comunicaciones mediadas por tecnología como publicaciones y comentarios en línea, se puede recuperar información asíncronamente. Y, en tercer lugar, abre la posibilidad de estudiar objetos que no son palpables, pero que existen y significan 
culturalmente, aunque desde la virtualidad y, en varias ocasiones, gracias a ella.

Por este carácter adaptativo y flexible, la etnografía digital ha derivado en una diversificación de los objetos de estudio abordados. No obstante, sus observables se han mantenido relativamente estables, sean tangibles o no. En el libro de Pink et al. (2019), sobre los principios y las prácticas de la etnografía en el mundo digital, estos señalan siete tipos de observables, cada uno con sus alcances y limitaciones: experiencias, prácticas, cosas, relaciones, mundos sociales, localidades y eventos. En este artículo el diseño metodológico propuesto está orientado al estudio de las prácticas.

\section{La etnografía digital en el estudio de las prácticas}

"Práctica" proviene etimológicamente del vocablo griego praxus, que significa "toda la actividad humana concreta y tiene por antónimo el término teoría" (CLACSO-ILDIS, 1976, p.166). Afortunadamente, de acuerdo a Reckwitz (2002), han sido muchos teóricos como Bourdieu, Giddens, Schatzki, Garfinkel y Latour, entre varios más, los que han colaborado a delimitar el estudio de las prácticas sociales. Sobre esta conceptualización el autor menciona:

La "práctica" (praxis) en singular representa simplemente un término enfático para describir el conjunto de la acción humana (en contraste con la "teoría" y el mero pensamiento). "Prácticas" en el sentido de la teoría de las prácticas sociales, sin embargo, es otra cosa. Una 'práctica' (praktik) es un tipo de comportamiento rutinario que consta de varios elementos, interconectados entre sí: formas de actividades corporales, formas de actividades mentales, 'cosas' y su uso, un conocimiento de fondo en forma de comprensión, un saber cómo, estados de emoción y conocimiento motivacional (Reckwitz, 2002, p. 249).

Su definición rescata la importancia de vincular las prácticas sociales con sus aspectos circundantes. A esto mismo apuntan Sarah Pink y sus colabora- dores cuando mencionan que "los estudiosos interesados en las prácticas se ocupan de entender la relación entre las actuaciones humanas y las normas, las estructuras y los procesos en que se asienta lo que la gente dice y hace" (Pink et al., 2019, p. 62). Trasladando estos principios a la lectura y la escritura, estas se pueden considerar prácticas sociales en tanto actividades cotidianas que incluyen corporalidad en la manipulación de los diversos soportes, pueden recaer en objetos físicos o dispositivos digitales, dan pauta al intercambio de ideas entre los sujetos e intervienen en sus lecturas del mundo que habitan y significan.

Ahora bien, visibilizar las prácticas de lectura y escritura anidadas a los usos cotidianos presenta algunos retos. De acuerdo a Barton \& Hamilton (2000, p. 8), las prácticas de literacidad pueden observarse a través de los eventos letrados, entendidos como “episodios observables que surgen de las prácticas y son moldeados por ellas" y son identificables en tanto que "hay un texto escrito, o textos, centrales para la actividad y puede haber conversaciones en torno al texto". Es decir, los eventos letrados representan la dimensión observable de las prácticas de literacidad como una actividad socialmente situada. Por eso, se sugiere que al analizar eventos letrados se tome en cuenta que hay nuevos lenguajes y objetos culturales digitales que mediatizan la cultura escrita, en la que prima el valor de la diversidad y la libertad, en una interacción de tipo horizontal facilitada por los medios virtuales (Martos et al., 2009).

En la revisión de la literatura se identificó que especialmente el enfoque sociocultural de los NEL puede beneficiarse de las aportaciones del método etnográfico, pues hace posible el análisis situado de las prácticas (Moreno \& Sito, 2019). En estudios anteriores la recuperación de los eventos letrados se ha logrado por diversos medios, como relojes de lectura, registros, observaciones o notas de campo. La Tabla 1 presenta un resumen de algunas técnicas de recolección implementadas en la investigación de la lectura y la escritura desde el enfoque etnográfico (digital y tradicional). 


\section{Tabla 1}

Estudios que han abordado la lectura o la escritura desde un abordaje etnográfico con sus instrumentos de recolección de información

\begin{tabular}{|c|c|c|c|c|}
\hline Autores & Estudio & Año/País & Aborda & $\begin{array}{l}\text { Técnicas de recolección de } \\
\text { información }\end{array}$ \\
\hline Julia Guillen & $\begin{array}{l}\text { Literacy practices in Schome } \\
\text { Park: a virtual literacy } \\
\text { ethnography }\end{array}$ & $\begin{array}{l}2009 \\
\text { Reino Unido }\end{array}$ & $\begin{array}{l}\text { Interacciones de } \\
\text { estudiantes y tutores } \\
\text { en un programa de } \\
\text { alfabetización realizado } \\
\text { en un mundo virtual }\end{array}$ & $\begin{array}{l}\text {-Registro del tiempo de las } \\
\text { intervenciones hechas por los } \\
\text { alumnos } \\
\text {-Identificación de los hablantes } \\
\text {-Enumeración de las } \\
\text { participaciones } \\
\text {-Foros y Wiki: capturas de } \\
\text { pantalla con fechas. }\end{array}$ \\
\hline $\begin{array}{l}\text { Sylvia Wolfe \& } \\
\text { Rosie Flewitt }\end{array}$ & $\begin{array}{l}\text { New technologies, new } \\
\text { multimodal literacy } \\
\text { practices and young } \\
\text { children's metacognitive } \\
\text { development }\end{array}$ & $\begin{array}{l}2010 \\
\text { Reino Unido }\end{array}$ & $\begin{array}{l}\text { Procesos de aprendizaje } \\
\text { de la lectoescritura a } \\
\text { través de diferentes } \\
\text { medios por parte de } \\
\text { niños de } 3 \text { a } 4 \text { años. }\end{array}$ & $\begin{array}{l}\text {-Revisión de documentos } \\
\text {-Cuestionarios } \\
\text {-Observaciones } \\
\text {-Entrevistas semi-estructuradas }\end{array}$ \\
\hline $\begin{array}{l}\text { Aurora María Ruiz- } \\
\text { Bejarano }\end{array}$ & $\begin{array}{l}\text { Hacia una etnografía de } \\
\text { la lectura escolar. Prácticas } \\
\text { y representaciones de la } \\
\text { lectura en la escuela }\end{array}$ & $\begin{array}{l}2016 \\
\text { España }\end{array}$ & $\begin{array}{l}\text { Prácticas, } \\
\text { representaciones y usos } \\
\text { de la lectura en una } \\
\text { escuela de educación } \\
\text { básica }\end{array}$ & $\begin{array}{l}\text {-Observación de espacios } \\
\text { letrados/eventos letrados } \\
\text {-Observación de espacios físicos } \\
\text {-Entrevistas } \\
\text {-Conversaciones informales } \\
\text {-Análisis de documentos }\end{array}$ \\
\hline $\begin{array}{l}\text { Pamela Jiménez } \\
\& \\
\text { Marco Lovón }\end{array}$ & $\begin{array}{l}\text { Literacidad y etnografía: } \\
\text { La escritura generada en los } \\
\text { mercados comerciales }\end{array}$ & $\begin{array}{l}2017 \\
\text { Perú }\end{array}$ & $\begin{array}{l}\text { Prácticas de escritura } \\
\text { de compradores y } \\
\text { vendedores en un } \\
\text { mercado }\end{array}$ & $\begin{array}{l}\text {-Observación de las prácticas de } \\
\text { escritura en el ambiente natural } \\
\text { de los comerciantes (el mercado). } \\
\text {-Entrevistas personales }\end{array}$ \\
\hline $\begin{array}{l}\text { Francisco Martínez- } \\
\text { Ortega } \\
\& \\
\text { Boris Vázquez- } \\
\text { Calvo }\end{array}$ & $\begin{array}{l}\text { El aprovechamiento de } \\
\text { prácticas letradas digitales } \\
\text { en Educación Secundaria } \\
\text { Obligatoria: acercamiento } \\
\text { etnográfico en un instituto } \\
\text { de Barcelona }\end{array}$ & $\begin{array}{l}2018 \\
\text { España }\end{array}$ & $\begin{array}{l}\text { Prácticas letradas } \\
\text { digitales en una escuela } \\
\text { secundaria de España, } \\
\text { que ha mantenido } \\
\text { el programa de una } \\
\text { computadora por } \\
\text { alumno }\end{array}$ & $\begin{array}{l}\text {-Observaciones } \\
\text {-Revisiones de documentos } \\
\text {-Grabaciones de audio } \\
\text {-Entrevistas } \\
\text {-Fotografías }\end{array}$ \\
\hline
\end{tabular}

Nota: elaboración propia con los datos de Guillen (2009), Wolfe \& Flewitt (2010), Ruiz \& Bejarano (2016), Jiménez \& Lovón (2017), y Martínez, Ortega \& Vázquez Calvo (2018).

No obstante, el estudio de las prácticas por medio de la etnografía digital, como todo método, tiene alcances y limitaciones. Por una parte, es una metodología pertinente cuando se pretende visibilizar rutinas digitales habituales que por su ejecución en la vida cotidiana habían permanecido ocultas o latentes (Pink et al., 2019). Por otra parte, al ser un método que recupera datos a profundidad, suele tener un tamaño reducido de muestra, lo que impide la generalización de los resultados a grupos poblacionales más amplios. 


\section{Metodología}

La muestra de este estudio surgió de la aplicación de un cuestionario en línea de 62 ítems en el que se identificaron diversas prácticas de lectura y escritura, con una serie de preguntas cerradas que diferenciaban las actividades realizadas por asignación de aquellas que se efectuaban por placer. Este fue contestado por 2,650 estudiantes activos de la Universidad de Guadalajara en el semestre 2020-A, cursando algún programa educativo a nivel de Licenciatura o Técnico Superior Universitario de centros metropolitanos y regionales. Rosas, Sánchez \& Lozoya (2020) explican los principales resultados obtenidos del cuestionario aplicado; sin embargo, en el marco de este documento nos enfocaremos en lo encontrado por medio de la etnografía digital, que consistió en la fase cualitativa.
De acuerdo a las respuestas del cuestionario, se midieron los factores de afectividad, aprestamiento, autonomía cultural, educacional, inmersión, metacognición, periodicidad, procesamiento, recursividad y de utilidad. Con esto se calculó un índice lector por cada estudiante y se invitó a participar a la fase etnográfica a estudiantes en los extremos del índice para observar las prácticas de sujetos con hábitos de lectura distintos. Después de las sesiones informativas en línea, se contó con la confirmación de participación de 10 alumnos activos (aunque solo cinco cubrieron el total de momentos de la investigación): seis fueron hombres y cuatro mujeres, con edades comprendidas entre los 19 y los 28 años. La Tabla 2 muestra la participación de los estudiantes, con sus principales características:

\section{Tabla 2}

Muestra del estudio etnográfico digital

\begin{tabular}{|c|c|c|c|c|c|c|c|c|}
\hline Pseudónimo & Edad & $\begin{array}{l}\text { Índice } \\
\text { lector }\end{array}$ & Sexo & 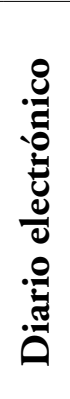 & 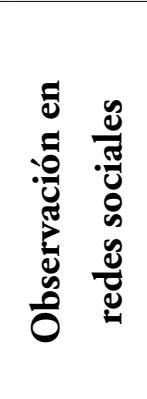 & 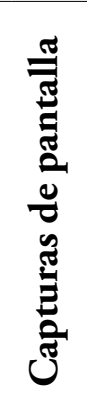 & 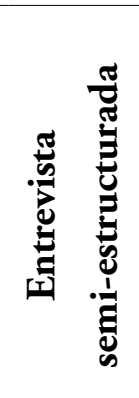 & 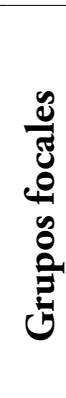 \\
\hline Elisa & 19 & 0.53 & Mujer & $\mathrm{X}$ & $\mathrm{X}$ & $\mathrm{X}$ & $\mathrm{X}$ & $\mathrm{X}$ \\
\hline Condial & 19 & 0.92 & Hombre & $\mathrm{X}$ & $\mathrm{X}$ & $\mathrm{X}$ & $\mathrm{X}$ & $\mathrm{X}$ \\
\hline Ruive & 20 & 0.88 & Hombre & $\mathrm{X}$ & $\mathrm{X}$ & $\mathrm{X}$ & & \\
\hline Pinod & 20 & 0.88 & Mujer & $\mathrm{X}$ & $\mathrm{X}$ & $\mathrm{X}$ & & \\
\hline Napel & 20 & 0.83 & Hombre & $\mathrm{X}$ & $\mathrm{X}$ & $\mathrm{X}$ & $\mathrm{X}$ & \\
\hline Leifr & 20 & 0.58 & Hombre & $\mathrm{X}$ & $\mathrm{X}$ & $\mathrm{X}$ & $\mathrm{X}$ & $\mathrm{X}$ \\
\hline Noble 6 & 21 & 0.9 & Hombre & $\mathrm{X}$ & $\mathrm{X}$ & $\mathrm{X}$ & $\mathrm{X}$ & $\mathrm{X}$ \\
\hline Padan & 21 & 0.85 & Mujer & $\mathrm{X}$ & $\mathrm{X}$ & $\mathrm{X}$ & $\mathrm{X}$ & \\
\hline Vafed & 27 & 0.83 & Hombre & $\mathrm{X}$ & $\mathrm{X}$ & $\mathrm{X}$ & & \\
\hline Horcrux91 & 28 & 0.55 & Mujer & $\mathrm{X}$ & $\mathrm{X}$ & $\mathrm{X}$ & $\mathrm{X}$ & $\mathrm{X}$ \\
\hline
\end{tabular}


Aplicación de la etnografía digital en el estudio de las prácticas de lectura y escritura

La propuesta de etnografía digital se instrumentó considerando la pregunta de investigación de cuáles son las prácticas vernáculas de lectura y escritura de los estudiantes universitarios, así como el objetivo general de identificar los factores que determinan sus hábitos vernáculos de lectura y escritura. $\mathrm{Al}$ respecto, se consideraron cuatro variables con sus dimensiones, que fueron indagadas a través de cinco instrumentos. La Figura 1 muestra una versión sintética de la relación de las variables-dimensión-instrumentos que permitieron la triangulación de métodos en la recolección de los datos.

\section{Figura 1}

Variables y dimensiones de la investigación con la triangulación de métodos
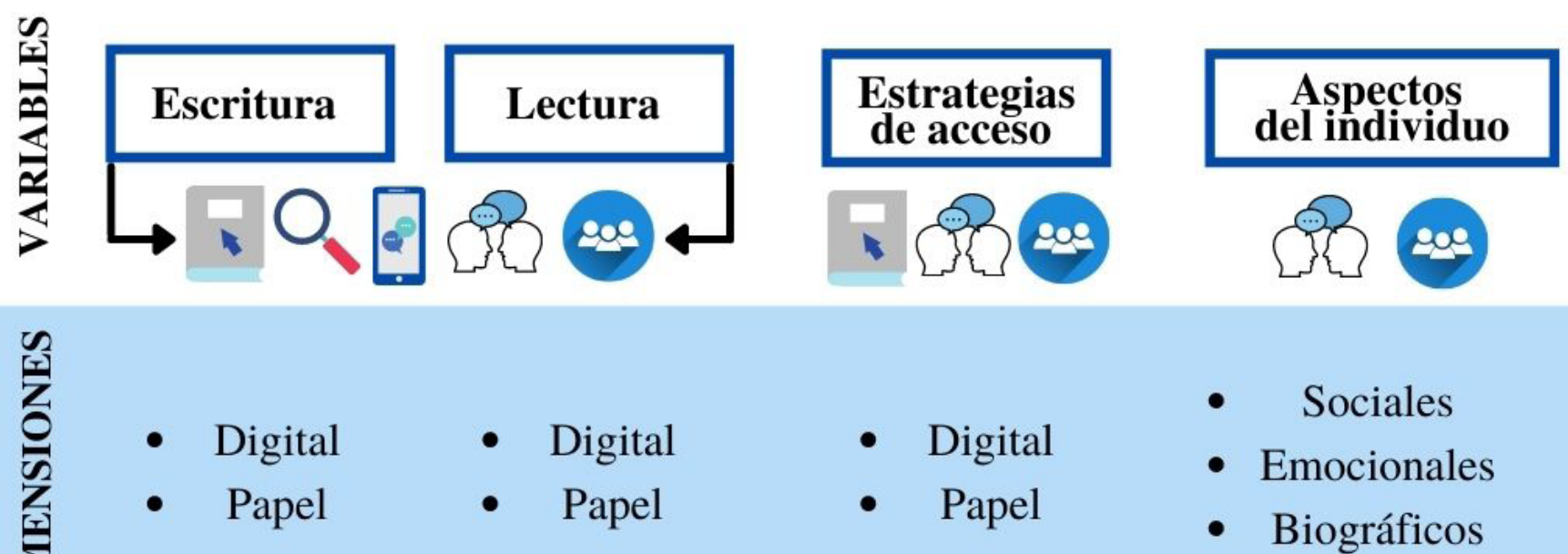

- Sociales

- Emocionales

- Biográficos

- Económicos

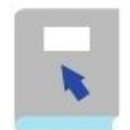

Diario electrónico

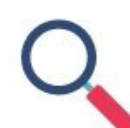

Observación de redes sociales

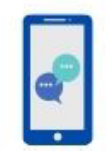

Capturas de pantalla

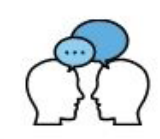

Entrevistas semiestructuradas
200

Grupos
Por medio de cada instrumento se recuperaron una serie de datos específicos utilizando diversas herramientas digitales, con lo cual fue posible el desarrollo de la investigación de campo sin necesidad de interacción presencial durante las siete semanas de la recolección de datos, como se muestra en la Tabla 3. 


\section{Tabla 3}

Estrategia de recolección de datos implementados en la metodología de etnografía digital sobre las prácticas de lectura y escritura en estudiantes universitarios

\begin{tabular}{llll}
\hline \multicolumn{1}{c}{$\begin{array}{c}\text { Instrumentos de } \\
\text { recolección de datos }\end{array}$} & \multicolumn{1}{c}{ Datos recuperados } & Plataformas utilizadas & Duración \\
\hline & 1.1 Tipo de actividad de (lectura o escritura) & \\
& 1.2 Fecha & -Google Forms & \\
& 1.3 Hora en que se realizó y su duración & personalizado (para uso & 7 semanas \\
1. Diario electrónico & 1.4 Tipo de soporte (digital o impreso/papel) & de cada participante) & \\
de eventos letrados & 1.5 Descripción de la actividad & -Recordatorio vía e-mail & \\
& 1.6 Relación con un ámbito de su vida & & \\
& 1.7 Espacio para adjuntar una fotografía & & \\
\hline
\end{tabular}

\section{Publicaciones:}

Día y hora de publicación

1.1 Red social

1.2 Tipo de actividad (lectura, escritura o ambas)

1.3 Número de palabras

\section{Observación de} prácticas de lectura y escritura en redes sociales
1.4 Finalidad comunicativa

1.5 Vinculación a un nivel cognitivo

1.6 Usuarios que comentaron o reaccionaron

1.7 Tipos de reacciones y comentarios

1.8 Idioma

1.9 Recursos que acompañaban la publicación

1.10Autoría (propia o de un tercero)

Historias: Las mismas que en las publicaciones, a excepción de los puntos 2.7 y 2.8 , que no son visibles en el formato de historias.

\author{
-Google Forms para \\ sistematizar diariamente \\ observaciones (para uso \\ del Cuerpo Académico) \\ -Cuenta especial para \\ 7 semanas \\ la investigación en \\ Facebook, Twitter e \\ Instagram.
}

3. Solicitud de
capturas de pantalla
de conversaciones
entorno a la lectura y
la escritura

4. Entrevistas

semiestructuradas en

línea a la escritura

1.1 Aspectos biográficos

1.2 Aspectos sociales

1.3 Aspectos económicos

1.4 Aspectos emocionales

1.5 Estrategias de acceso

\section{Participación en un grupo focal en línea}

1.1 Conversaciones digitales no publicadas en torno a la lectura

1.2 Conversaciones digitales no publicadas en torno a la escritura
1.1. Reflexiones de sus prácticas de lectura y escritura al participar en la investigación
videoconferencia Zoom
-Presentación de tópicos en Canva

-Sistema de

-Vía e-mail segunda semana -Carpetas de Google de la investigación

Drive
-Sistema de

videoconferencia Zoom
Al primer mes de observación de redes sociales en línea se solicitó semanalmente

A partir de la
Al cierre de la

observación de redes

sociales en línea 
Para recuperar un registro de los eventos letrados cotidianos de los participantes se instrumentó un formulario personalizado en línea que ellos conocieron como un "Diario de lectura y escritura" (una muestra del instrumento puede consultarse en https://forms. gle/HFrFjb2itBWeCaQ98 ). A modo de recordatorio, se programó un correo electrónico semanal para que los universitarios registraran sus actividades de lectura y escritura, ya sea por placer o asignación.

Sobre las prácticas de escritura se pidió el consentimiento informado de los participantes para agregarlos en sus redes sociales en línea (Facebook, Instagram, Twitter) a través de una cuenta creada específicamente para realizar la observación no participante por siete semanas. Dos colaboradores del cuerpo académico registraron diariamente las publicaciones e historias de cada participante, sistematizándolas por medio de formularios en línea (ambos instrumentos de libre consulta en https://forms.gle/ hX27Lbf1R4XtAPyc6 y https://forms.gle/oZytsHvESoskufY27, respectivamente).

Una técnica complementaria para recuperar la lectura y escritura como prácticas situadas que no fueran publicadas online, fue la solicitud de capturas de pantalla en las que los jóvenes socializaban un texto o un fragmento leído o escrito con una o más personas por un medio privado. Estas también se solicitaron semanalmente por correo electrónico y se organizaron en carpetas en la nube.
Por último, las técnicas de entrevistas personales y de grupo focal realizadas en línea a la mitad y al cierre de la investigación permitieron la recuperación de datos puntuales sobre las prácticas de lectura y escritura de los participantes que ya se habían observado con la intención de afinar el marco interpretativo.

A modo de síntesis sobre el diseño metodológico, se consideró una fortaleza la estructuración de una diversidad de técnicas de recolección de datos, pues permitió la triangulación y contrastación de la información cualitativa y esta, a su vez, fue valiosa para cotejar con los datos cuantitativos del cuestionario. Además, hizo posible llevar a término una investigación totalmente online, hecho de alto valor considerando que las fechas de este estudio estuvieron enmarcadas en las jornadas de confinamiento por el virus SARS-CoV-2.

\section{Resultados}

Los diarios digitales de eventos letrados nos permitieron conocer una variedad de rutinas, preferencias en soportes y horarios en cada uno de los participantes. Para ilustrar esta comparativa se presentan las Figuras 2 y 3 con los registros de la participante Elisa, y las Figuras 4 y 5 con los registros de Noble 6 (seudónimos elegidos por ambos participantes).

\section{Figura 2}

Registros en el diario de eventos letrados de Elisa con duración y tipo de soporte

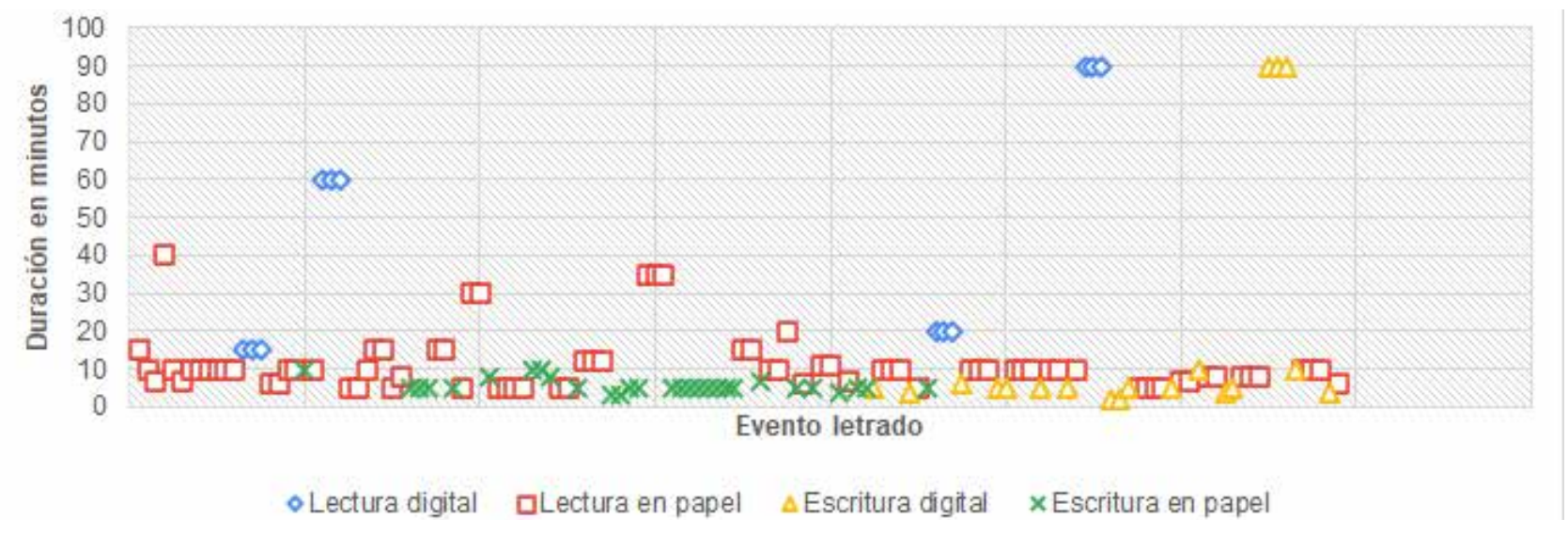

Nota: el total de eventos letrados registrados por Elisa fueron 138 y se muestran en la gráfica en el orden de registro, de izquierda a derecha. 


\section{Figura 3}

Horarios registrados de eventos letrados de Elisa en su diario

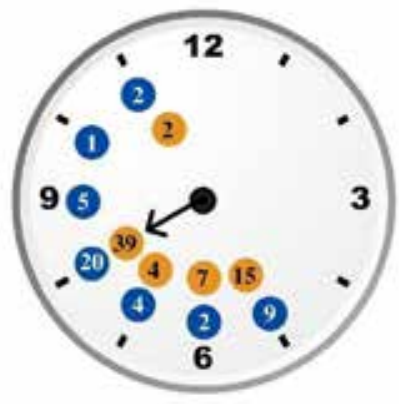

$\mathrm{AM}$

Número de eventos de escritura

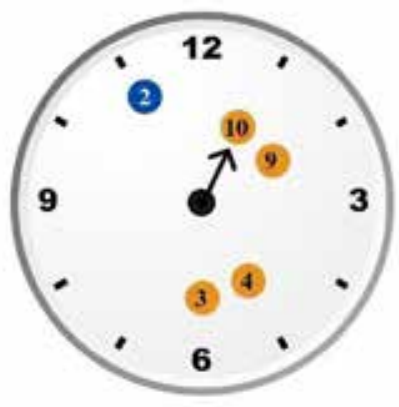

PM

Número de eventos de lectura
Nota: el número dentro del círculo indica la cantidad de eventos registrados a esa hora, mientras la flecha señala el horario de mayor recurrencia.

Elisa es una estudiante de la Licenciatura en Médico Cirujano y Partero, tiene 19 años, se dedica completamente a sus estudios y vive con su familia. Como se presenta en la Figura 2, se puede observar que los eventos de lectura fueron mayores $(n=93)$ a los de escritura $(\mathrm{n}=45)$; además, que los períodos de lectura tuvieron picos de duración más altos (de hasta 90 minutos) que los de escritura (máximo de 10 minutos). No obstante, respecto a los soportes es interesante notar que, aunque la lectura digital es menos frecuente para esta universitaria, la duración es más alta que al realizarla en impreso; en cuanto a la escritura, es notorio que hubo una transición en la práctica hacia la digitalidad durante el confinamiento; sin embargo, la duración se mantuvo de manera similar.

Además, respecto a los horarios en la Figura 3 es notable que las actividades de lectura y escritura de Elisa se concentran en los horarios diurnos, específicamente a las 8 a. m. Esto guarda relación con el tipo de eventos letrados registrados, pues se observa que tienen principalmente una función introspectiva y emocional: como parte de una rutina de inicio del día, Elisa realiza una lectura reflexiva y escribe en su diario personal razones por las cuales siente agradecimiento.

\section{Figura 4}

Registros en el diario de eventos letrados de Noble 6, con duración y tipo de soporte

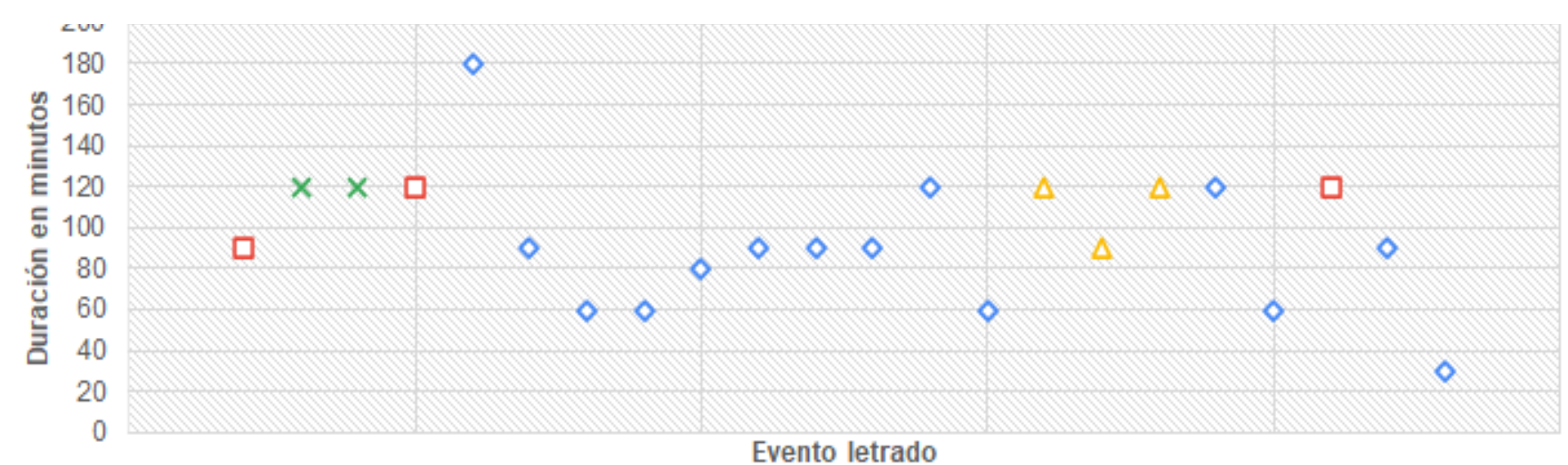

- Lectura digital aLectura en papel $\triangle$ Escritura digital $\times$ Escritura en papel

Nota: el total de eventos letrados registrados por Noble 6 fueron 22 y se muestran en el orden del registro, de izquierda a derecha. 


\section{Figura 5}

Horarios registrados de eventos letrados de Noble 6 en su diario

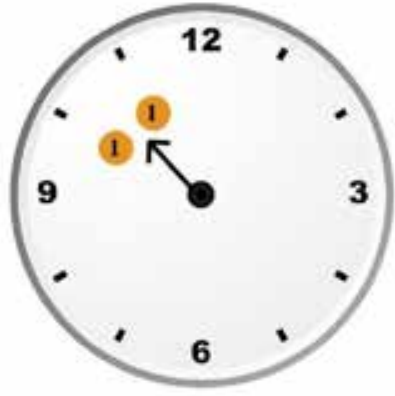

$\mathrm{AM}$
Número de eventos de escritura

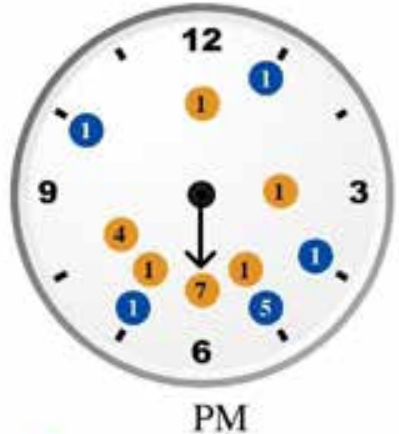

Número de eventos de lectura
Nota: el número dentro del círculo indica la cantidad de eventos registrados a esa hora, mientras la flecha señala el horario de mayor recurrencia.

Noble 6 es un estudiante de la Licenciatura en Administración Financiera y Sistemas, tiene 21 años y es foráneo, por lo cual vive solo en Guadalajara y divide su rutina diaria entre sus estudios y su trabajo. En la Figura 4 se puede observar que los eventos de lectura fueron mayores $(n=17)$ a los de escritura $(n=5)$, y aunque los períodos de ambas actividades tienen una duración parecida, el evento de lectura registrado con mayor duración fue de 180 minutos, mientras el de escritura fue de 120 minutos. En cuanto a los soportes, a diferencia de Elisa, Noble 6 registró actividades de lectura y escritura mayormente realizadas en digital $(n=17)$, más que en impreso o en papel $(n=5)$.

Además, respecto a los horarios, en la Figura 5 se identificó que sus eventos letrados registrados se llevaron a cabo principalmente por la tarde, particularmente concentrados entre las 5 p. m. y las 6 p. m. Estos horarios hacen sentido con el propósito de los eventos letrados que registró, pues existe una mayor relación con su ámbito laboral, como investigar conceptos y términos particulares de su trabajo y realizar apuntes para clarificar sus ideas, lo cual le da un enfoque más estratégico en cuanto a la adquisición de conocimiento.

Ahora bien, los diarios también incluían un espacio para agregar una pequeña descripción de qué fue lo que ellos leyeron y escribieron en ese registro, aspecto que fue propicio para explorar cuáles actividades ellos consideraban propiamente de lectura y escritura. En la categorización de la diversidad de estas actividades se encontró que, del total de los registros $(n=236)$, las dos principales lecturas fueron en referencia a libros $(\mathrm{n}=115)$ y artículos ( $\mathrm{n}=29)$; en cambio, al analizar las actividades de escritura, las dos principales menciones en los registros fueron reflexiones propias, como las realizadas en un diario personal $(n=47)$ y la redacción de bosquejos de obras propias $(n=4)$. Cabe destacar que únicamente un registro realizado por uno de los participantes de este estudio hizo mención a la lectura en sus redes sociales en línea y ningún registro mencionó alguna aplicación de mensajería instantánea para estos fines. Esto señala un arraigo a las expresiones convencionales de lectura y escritura, aun en los jóvenes.

Respecto a la observación de sus redes sociales, del total de participantes se recuperaron registros de 356 publicaciones. Se encontró que 196 estaban acompańadas de un texto escrito por los universitarios y, en promedio, contenían 15 palabras. No obstante, es necesario señalar que en las publicaciones restantes $(\mathrm{n}=160)$ no se acompañó de un texto escrito por ellos, simplemente se limitaron a recompartir una publicación de un tercero. Las Figuras 6 y 7 muestran los casos particulares de las publicaciones de Elisa y Noble 6. 


\section{Figura 6}

Publicaciones de Elisa por red social y número de palabras escritas por ella

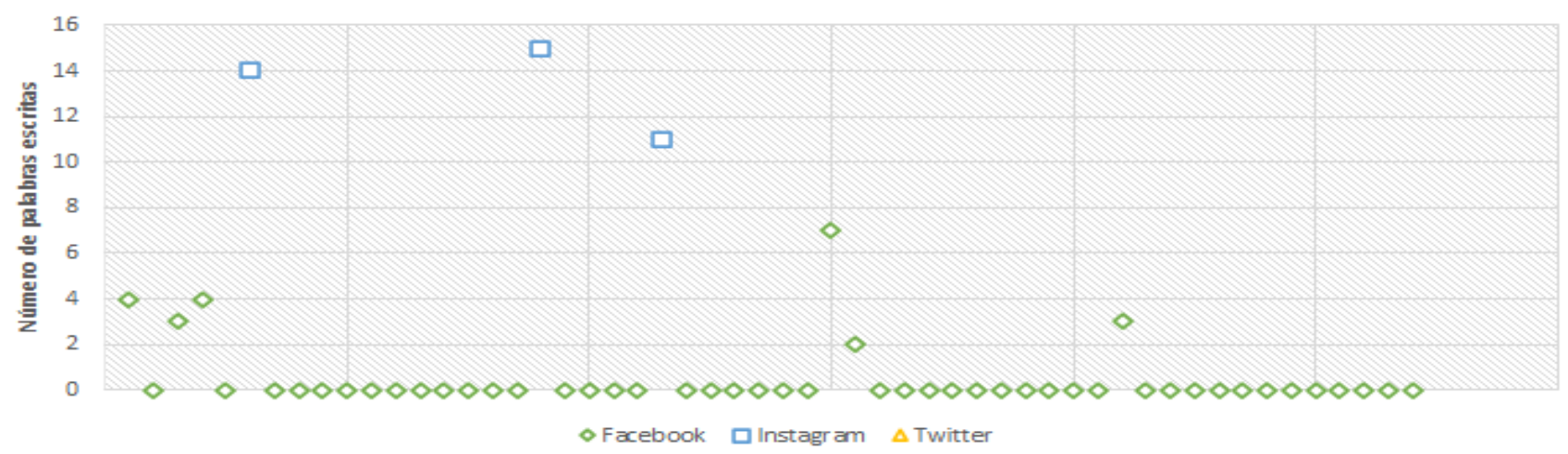

Nota: el total de publicaciones registradas en las redes sociales de Elisa fueron 54 y se muestran en el orden del registro, de izquierda a derecha.

\section{Figura 7}

Publicaciones de Noble 6 por red social y número de palabras escritas por él

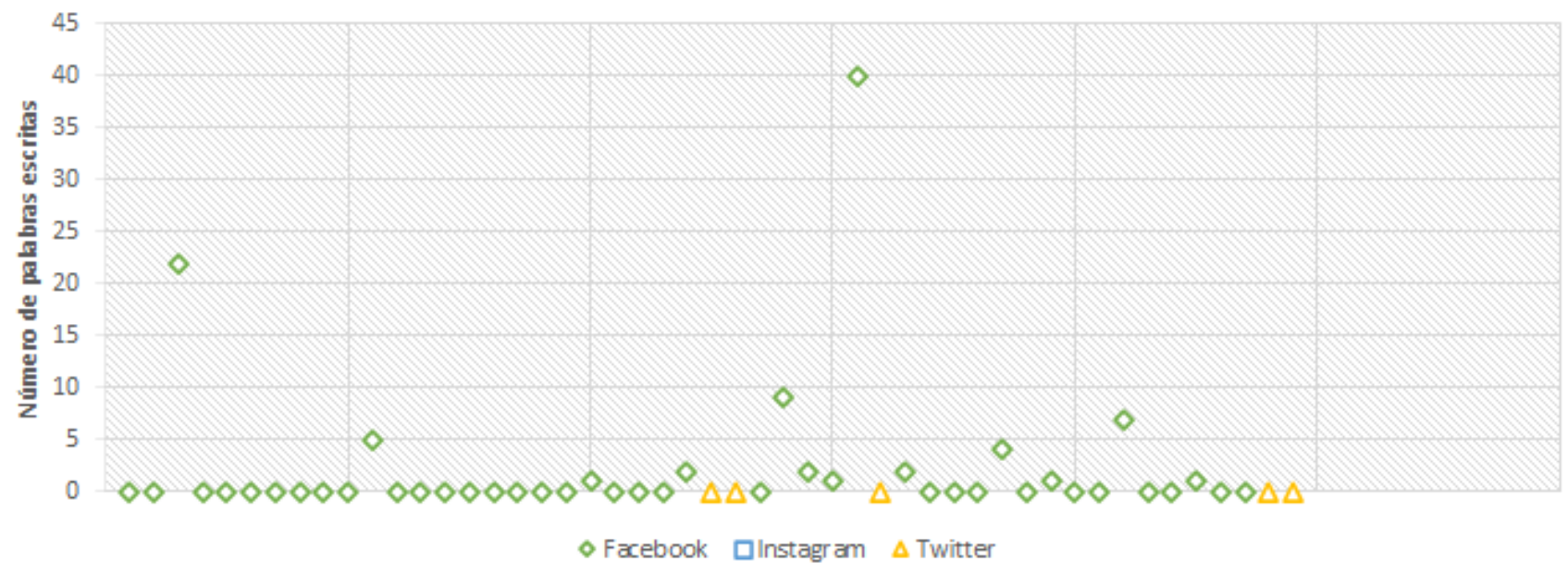

Nota: el total de publicaciones registradas en las redes sociales de Noble 6 fueron 49 y se muestran en el orden del registro, de izquierda a derecha.

En cuanto a Elisa, en la Figura 6 se puede observar que, aunque las publicaciones en Instagram son menores, cuando las realiza escribe más palabras (hasta 15) que en Facebook (máximo 7). En el caso de Noble 6, en la Figura 7 se muestra una dinámica distinta, en tanto que ha realizado publicaciones con mayor número de palabras escritas por él (hasta 40) y, al menos en el marco de este estudio, Twitter lo usó únicamente para recompartir publicaciones de terceros, sin agregar un texto escrito por él. De hecho, como queda evidenciado, en ambos participantes lo más recurrente fue publicar sin agregar palabras escritas 
por ellos. Una explicación tentativa de esto surgió en los grupos focales:

A veces mis mismos amigos de Facebook o WhatsApp si ven un texto gigantesco, no le toman mucha atención. Entonces agarro puntos centrales de las lecturas y digo: "Esto es impactante y va a llamar más la atención que un texto grande" (Condial, comunicación personal, 26 de septiembre 2020).

A propósito de las redes sociales en línea como un medio para compartir y socializar sus lecturas, hubo consenso en los participantes de preferir hacerlo de manera presencial porque cara-cara pueden leer los gestos y el tono del interlocutor a quien se dirigen, evitando malas interpretaciones en el intercambio de ideas o inclusive señalando un temor latente a la agresión verbal al comunicarse por medios digitales.

Además de esto, en los registros de observación de redes sociales se recuperaron los recursos que acompañaban las publicaciones además del texto, tales como imágenes, videos o inclusive enlaces. A continuación, la Figura 8 presenta la información comparativa de los recursos con los que Elisa y Noble 6 acompañaron sus publicaciones en Facebook, Instagram y Twitter.

\section{Figura 8}

Comparativa de recursos que acompañan las publicaciones de Elisa y Noble 6 en sus redes sociales en linea, independientemente de la escritura de texto

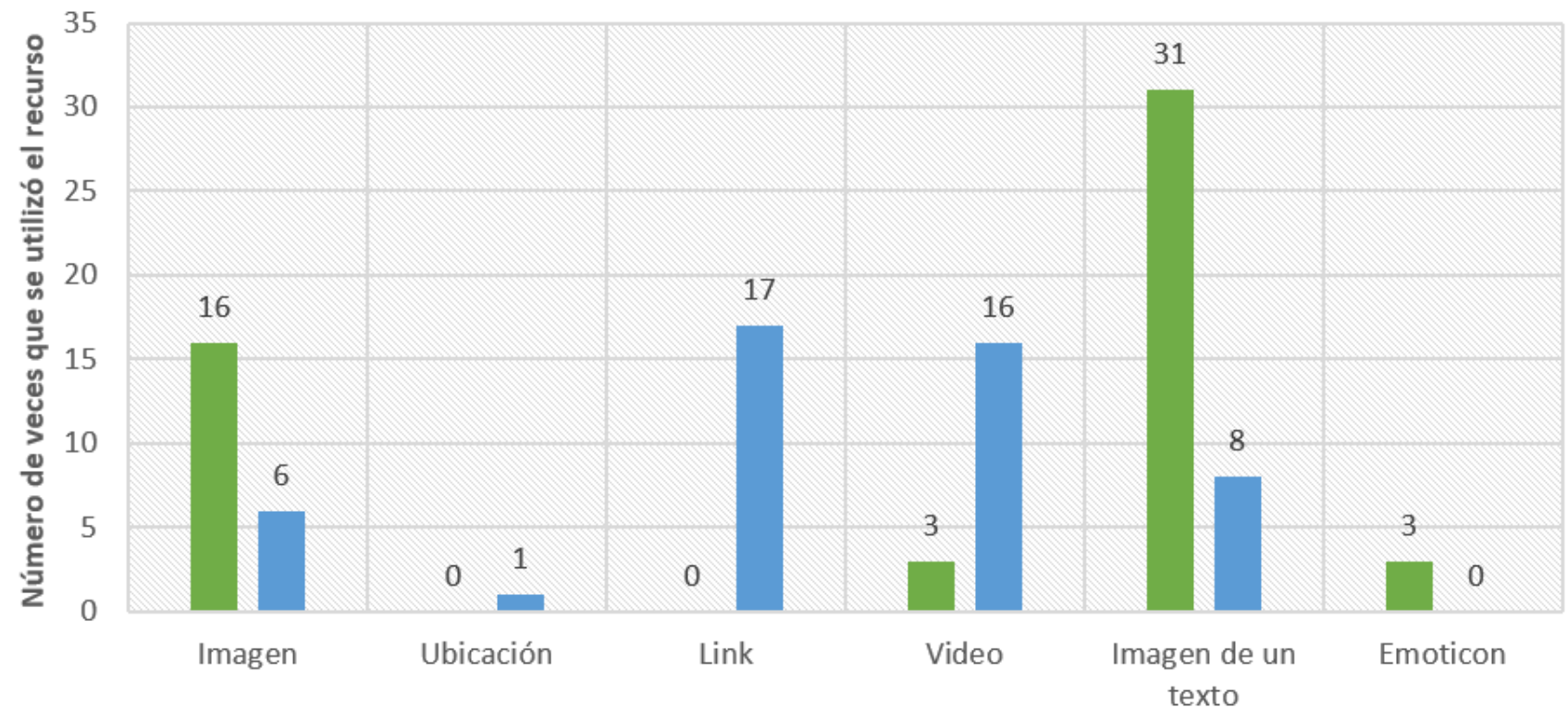

Tipo de recurso utilizado en las publicaciones

aLISA nOBLE 6

La diversidad de recursos que acompañan las publicaciones es muestra de cómo en estos espacios virtuales la lectura de texto se encuentra vinculada, prácticamente de forma paralela, a otro tipo de lecturas. Se observó de manera regular la integración de imágenes ilustrativas a un texto, como fotografías o dibujos; el video con palabras expresadas en voz de un narrador o en texto dentro del video; así como las imágenes de un texto, que incluían infografías, fotografías con frases o los llamados memes, que combinan fotografías o ilustraciones con algún texto.

Lo cierto es que el texto se ha integrado de diversas maneras en la comunicación mediada por redes sociales en línea, al menos por parte de los universitarios de 
este estudio. Se trata de lecturas en las que su complejidad trasciende el número de palabras integradas, son lecturas de imágenes estáticas o en movimiento que se encuentran cada vez más conectadas y responden profundamente a las preferencias y los valores de la cultura juvenil.

En cuanto a las capturas de pantalla de conversaciones privadas sobre la lectura o la escritura, estas fueron útiles para identificar que las recomendaciones y reflexiones más profundas pasan por este canal, más directo y horizontal, en lugar de publicarlo en sus redes sociales en línea, como se ilustra en la Figura 9.

\section{Figura 9}

Captura de pantalla proporcionada por Elisa al recomendar un libro de manera privada

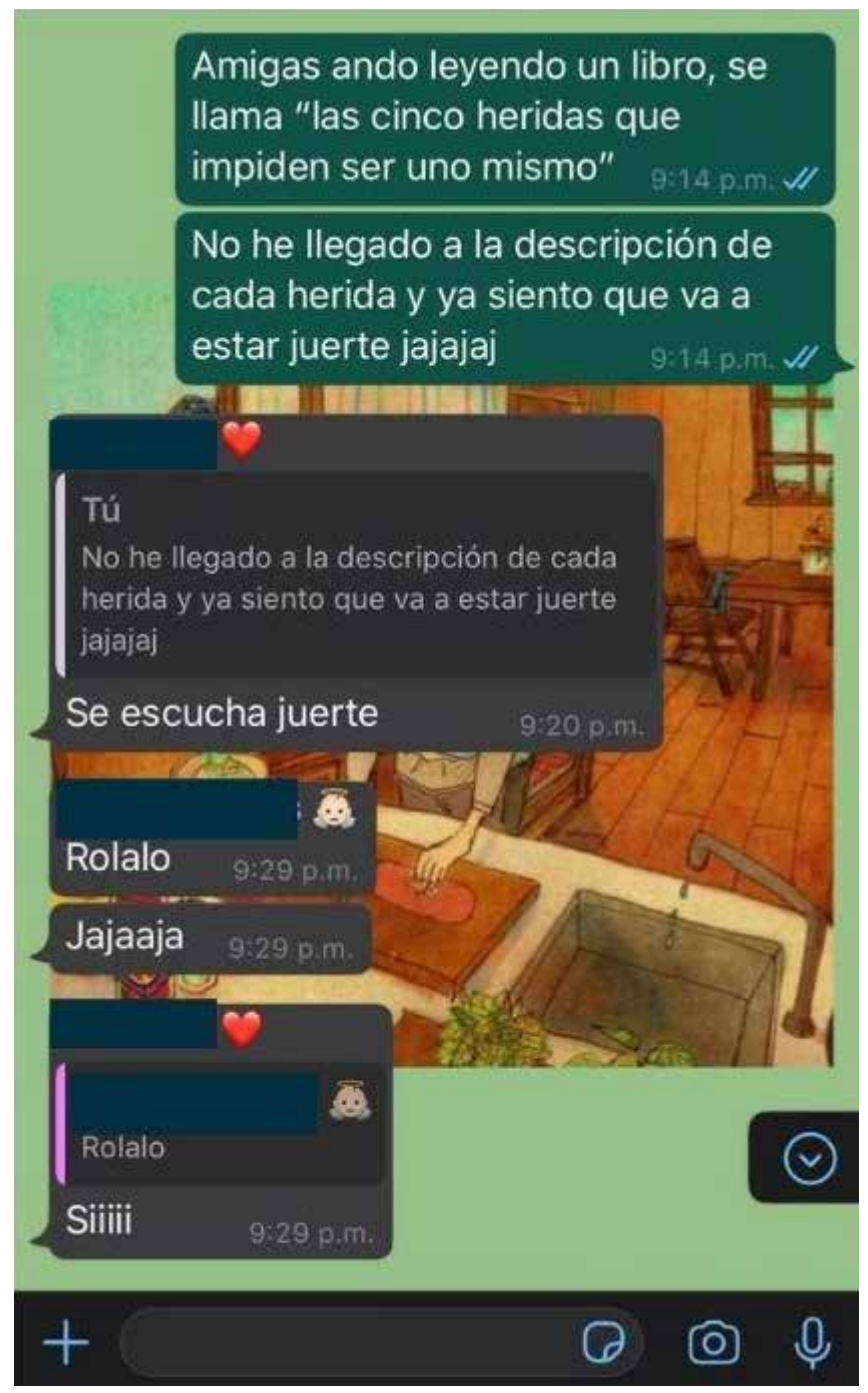

En la Figura 9 se visualiza una conversación privada de Elisa con un grupo de amigas por medio de una aplicación de mensajería al momento en que les recomienda un libro que comenzó a leer por placer. Este tipo de escenas fueron útiles para comprender que las lecturas suelen ser socializadas o discutidas entre pares en núcleos cerrados, seguros y con personas de su confianza, delegando en buena medida a las redes sociales en línea la función de compartir o recompartir información de terceros, actividad que poca escritura les demanda.

Por supuesto, por medio de las entrevistas se obtuvo una gran cantidad de datos que constituyeron la base interpretativa de las prácticas observadas. No obstante, en cuanto al acceso a la lectura se encontró que una vez que los jóvenes desarrollaron el gusto por leer por iniciativa propia, han utilizado estratégicamente Internet para enterarse de nuevas obras; ejemplo de esto son las video-reseñas de libros que encuentran en YouTube, de los blogs con los Top 10 de un género literario o las páginas de Facebook que recomiendan libros e interconectan a lectores. A propósito de esto, presentamos un relato recuperado en la entrevista semiestructurada de uno de los participantes del estudio que vive en un entorno rural:

Sí, pues Facebook tiene esa bonita maravilla de que puedes conocer a gente de muchos lugares del mundo y ahí hay participación de muchos lugares. Entonces aparte de que comparten mucho material bibliográfico, puedes conocer e interactuar con más personas y compartir tus gustos y opiniones sobre diferentes materiales literarios y ver sus puntos de vista desde una perspectiva social diferente. (Condial, comunicación personal, 27 de agosto 2020)

Este aspecto es de alto valor, sobre todo en los jóvenes que crecieron en contextos socioculturales en los que la lectura no fue alentada o que actualmente no cuentan con un círculo amistoso ni familiar para socializar lo que leen. Para varios de estos casos el ciberespacio ha constituido un campo para conectar con la lectura y con los lectores, pese a que su entorno inmediato tangible sea ajeno. 


\section{Conclusiones y discusiones}

La identificación de las prácticas vernáculas de lectura y escritura de los universitarios por medio de etnografía digital permitió un acercamiento a los usos, las significaciones y los roles que tienen ambas actividades en su diario vivir, transitando constantemente de lo online a lo offline para llevarlas a cabo, muchas veces de manera complementaria más que dicotómica, por lo que proponemos denominarlas como lectura y escritura onlife.

Uno de los principales hallazgos fue que los ritmos e itinerarios de vida de los jóvenes afectan sus prácticas de lectura y escritura. Para los universitarios que combinan el estudio con actividades laborales es un desafío encontrar un tiempo y un espacio para la lectura -especialmente por placer- que puede superarse con una alta motivación intrínseca. Además, la significación de la lectura y la escritura en esta población puede responder a un enfoque reflexivo, introspectivo o catártico, o igualmente a uno pragmático o estratégico, independientemente de la aplicación académica.

Por otro lado, se encontró que Internet puede representar una herramienta de acercamiento a la lectura de la que particularmente podrían beneficiarse los jóvenes que no han crecido en ambientes lectores, aún más si se toma en cuenta el estimado de 8 horas y 21 minutos de navegación diaria en Internet (DataReportal, 2020). Esto concuerda con lo señalado por Paladines-Paredes \& Margallo (2020) sobre la mediación y socialización horizontal que realizan los jóvenes que producen, difunden y consumen el material audiovisual, impulsando entre pares un acercamiento a la lectura. No obstante, en este estudio se identificó que los universitarios buscan núcleos seguros y privados para compartir sus reflexiones sobre lo que leen.

La inclusión de elementos visuales que acompañaban la lectura que realizaron los jóvenes de este estudio señaló la importancia de la literacidad visual, pues coincidimos con Coiro (2003) y Gomes-Franco-e-Silva (2019) en que crecientemente la práctica de la lectura de texto se entreteje con la lectura de imágenes y videos en la construcción de sentido, indi- vidual y colaborativo, en entornos hiperconectados e interactivos. Esto conlleva a superar las concepciones tradicionales de la lectura, pues los mismos universitarios señalaron el acto de leer vinculado a libros, artículos y revistas. Específicamente fue notoria la falta de registros de eventos letrados que mencionaran el uso de redes sociales en línea o las aplicaciones de mensajería, indicando que ellos mismos aún tienen concepciones de tipo librodeterminista sobre lo que significa leer y escribir.

En cuanto a la escritura, los resultados obtenidos de las redes sociales en línea concuerdan con Chartier (Cordón \& Jarvio, 2015) sobre cómo la editorialización web ha promovido contenidos fragmentarios y menos profundos, pues los jóvenes escribieron en promedio 15 palabras en estos medios. Sin embargo, se considera que pueden ser un canal óptimo para la difusión de textos en nodos especializados a los cuales es necesario acercar a los estudiantes.

Respecto a los soportes, aunque varios de los participantes tuvieron predilección por el impreso o en papel para la lectura y la escritura -en concordancia con lo seńalado por Romero (2016)-, en la práctica acudieron al soporte digital por economía o accesibilidad desde dispositivos portátiles. Esta variación entre sus predilecciones y sus posibilidades provoca la entrada y salida constante de los entornos digitales, mezclando lo online con lo offline en sus eventos de literacidad.

En torno a la dimensión metodológica, se reconoce que la implementación de la etnografía digital fue pertinente para el estudio de las prácticas vernáculas de lectura y escritura de los universitarios; y sus redes sociales en línea, al no estar reguladas por ninguna institución, nos brindaron un campo óptimo para la observación. Además, porque la recolección de datos mediada por TIC hizo posible acceder a los eventos letrados cotidianos que ejecutan como parte de su vida privada, no publicada.

Hablando de las limitaciones, se identificó la necesidad de integrar mecanismos que contrasten las prácticas que los universitarios dicen hacer y las que realmente efectúan. En este estudio, por el confi- 
namiento mencionado, solo fue posible conocer los eventos letrados offline a través de los registros de los diarios electrónicos, medio por el cual algunos universitarios compartieron con los investigadores fotografías de sus notas, reflexiones escritas en papel, fragmentos leídos en libros impresos y que no publicaban en sus redes sociales en línea.

Epistemológicamente, la articulación del enfoque de los NEL con el método etnográfico fue posible ya que ambos han reconocido su encuentro con lo digital, concordando en que son las prácticas y los usos que los sujetos hacen de la tecnología lo que forma $-y$ transforma- su realidad social. Así pues, es conveniente detenerse a reflexionar: si la lectura y la escritura como objetos de estudio se encuentran en transformación constante a partir de la utilización de medios digitales, ¿cuánto tiempo más podremos continuar implementando métodos que no contemplen estos medios? En este sentido, se considera de alto valor contar con metodologías afines y flexibles que puedan adaptarse a la velocidad de la evolución de los objetos de estudio que aborda. Al menos en este estudio fue posible comprobar que la etnografía digital constituye un camino fructífero para el análisis de cómo los universitarios viven, practican, perciben y significan la lectura y la escritura desde su cotidianidad.

Efectivamente, las herramientas tecnológicas continuarán evolucionando y los sujetos seguirán apropiándolas de diversas maneras en sus prácticas cotidianas de lectura y escritura. Por lo tanto, la estrategia metodológica presentada en este artículo no intenta ser prescriptiva ni definitoria. En todo caso, representa una versión dentro de un amplio marco de posibilidades que espera impulsar la realización de futuros estudios que exploren sus alcances.

\section{Referencias}

A leer/IBBY México - Banamex. (2015). Primera Encuesta Nacionalsobre Consumo de Medios Digitales y Lectura. https://www.ibbymexico.org. mx/wp-content/uploads/2019/07/PEN03noviembre15-1.pdf
Apud, P. I. (2013). Repensar el método etnográfico hacia una etnografía multitécnica, reflexiva y abierta al diálogo interdisciplinario. Antipo. Rev. Antropol. Arqueol, 16, 213-235. ISSN 19005407. https://revistas.uniandes.edu.co/doi/pdf/ 10.7440/antipoda16.2013.10

Bárcenas, K. /\& Preza, N. (2019). Desafíos de la etnografía digital en el trabajo de campo onlife. Virtualis, 10(18), 134-151. ISSN 2007-2678. https://www.revistavirtualis.mx/index.php/ virtualis/article/view/287/294

Barker, R. G. (1968). Ecological psychology. Stanford University Press.

Barton, D. (2007). Literacy: an introduction to the ecology of written language [2da. Ed.]. Willey-Blackwell.

Barton, D., \& Hamilton, M. (2000). Literacy practices. In Barton, D., Hamilton, M., Ivanic, R. (Eds.), Situated literacies. Reading and writing in context (pp. 7-15). Routledge.

Briones, G. (1989). La Investigación Etnográfica. En Programa Interdisciplinario de Investigadores en Educación, Módulo 2.

Cassany, D. (2005). Investigaciones y propuestas sobre literacidad actual: multiliteracidad, internet $y$ criticidad. Cátedra UNESCO para la Lectura y la Escritura. Universidad de Concepción. http://www2.udec.cl/catedraunesco/05CASSANY.pdf

Chartier, R. (2018). Libros y lecturas. Los desafíos del mundo digital. Revista de Estudios Sociales, 64, 119-124. https://doi.org/10.7440/res64. 2018.09

CLACSO-ILDIS. (1976). Términos Latinoamericanos para el Diccionario de Ciencias Sociales. Consejo Latinoamericano de Ciencias Sociales. http:// biblioteca.clacso.edu.ar/ar/libros/historico/ rama.pdf

Coiro, J. (2003). Comprensión de la lectura en Internet: ampliando lo que entendemos por comprensión de la lectura para incluir las nuevas competencias. http://www.eduteka.org/ediciones/recomendado17-8a.htm 
Cordón, J. \& Jarvio, A. (2015). ¿Se está transformando la lectura y la escritura en la era digital? Revista Interamericana de Bibliotecología, 38(2), 137-145. https://doi.org/10.17533/udea.rib. v38n2a05

Creswell, J. (2014). Research Design. Qualitative, Quantitative, and Mixed Method Approaches [4ta. Ed.]. Sage Publications.

Creswell, J. (2018). Qualitative Inquiry and Research Design. Choosing among Five Approaches [4ta. Ed.]. Sage Publications.

DataReportal. (2020). Digital 2020: México. We Are Social/ Hootsuite. https://datareportal.com/ reports/digital-2020-mexico

Goetz, J. \& LeCompte, M. (1988). Etnografía y diseño cualitativo en investigación educativa. Ediciones Morata.

Gomes-Franco-e-Silva, F. (2019). Alfabetizar para ver: la importancia de aprender a leer, comprender y analizar imágenes, Ocnos, 18(3), 48-58. https:// doi.org/10.18239/ocnos_2019.18.3.2103

Fetterman, D. (2010). Ethnography: Step by step [3rd ed.]. Sage Publications.

Floridi, L. (Ed.). (2015). The Onlife Manifesto Being Human in a Hyperconnected Era. Springer Open.

Gómez-Cruz, E. (2017). Etnografía celular: una propuesta emergente de etnografía digital. Virtualis, 8(16), 77-98. https://www.revistavirtualis. $\mathrm{mx} /$ index.php/virtualis/article/viewFile/251/209

Guillen, J. (2009). Literacy practices in Schome Park: a virtual literacy ethnography. Journal of Research in Reading, 32(1), 57-74. https://doi. org/10.1111/j.1467-9817.2008.01381.x

Hine, C. (2004). Etnografía virtual, Colección Nuevas Tecnologías y Sociedad, UOC. https://seminariosocioantropologia.files.wordpress. com/2014/03/hine-christine-etnografia-virtual-uoc.pdf

INEGI. (23 de abril de 2019). Población lectora en México con tendencia decreciente en los últimos cinco años. [Comunicado de prensa]. https://www.inegi.org. $\mathrm{mx} /$ contenidos/saladeprensa/boletines/2019/ EstSociodemo/MOLEC2018_04.pdf
Jiménez, P. \& Lovón, M. (2017). Literacidad y etnografía: La escritura generada en los mercados comerciales. Sociedad y Lengua, 92-106. Universidad Nacional Mayor de San Marcos. https://repositorioacademico.upc.edu.pe/bitstream/handle/10757/626407/381-1-890-110-20170707_Lovoton.pdf? sequence $=1 \&$ isAllowed $=\mathrm{y}$

Lankshear, C., \& Knobel, M. (2008). Digital Literacies: concepts, policies and practices. Peter Lang.

Leu, D. J., Jr., Kinzer, C.K., Coiro, J., Castek, J., \& Henry, L. A. (2013). New literacies: A duallevel theory of the changing nature of literacy, instruction, and assessment. In R.B. Ruddell \& D. Alvermann (Eds.), Theoretical Models and Processes of Reading [6ta. Ed.]. International Reading Association.

Martínez-Ortega, F. \& Vázquez-Calvo, B. (2018). El aprovechamiento de prácticas letradas digitales en Educación Secundaria Obligatoria: acercamiento etnográfico en un instituto de Barcelona. En Hernández y Hernández, D., Cassany, D. \& López González, R. [Coords.]. Prácticas de lectura y escritura en la era digital (pp. 29-51). Editorial Brujas.

Martos, E., Martos, A., Campos, M. \& Nuñez, G. (2009). Nuevos territorios de la lectura y la escritura, En Eloy Martos \& Tania M. K. Rösing (Coords.), Prácticas de lectura y escritura (pp. 261-316). Universidade de Passo Fundo.

Moreno, E. \& Sito, L. (2019). Discusiones actuales, oportunidades y horizontes en los estudios sobre literacidades en América Latina, Íkala, 24(2), 219-229. https://doi.org/10.17533/udea. ikala.v24n02a02

UNESCO. (1999). Declaración sobre la Ciencia y el Uso del Saber Cientifico. Organización de las Naciones Unidas para la Educación, la Ciencia y la Cultura. http://www.unesco.org/science/ wcs/esp/declaracion_s.htm

UNESCO. (2006). Literacy for Life. Organización de las Naciones Unidas para la Educación, la Ciencia y la Cultura. 
Paladines-Paredes, L-V. \& Margallo, A.-M. (2020). Los canales booktuber como espacio de socialización de prácticas lectoras juveniles. Ocnos, 19(1), 55-67. https://doi.org/10.18239/ocnos _2020.19.1.1975.

Pink, S., Horst, H., Postill, J., Hjorth, L., Lewis, T. \& Tacchi, J. (2019). Etnografia Digital: Principios y práctica. Ediciones Morata.

Piscitelli, A. (2006). Nativos e Inmigrantes digitales ¿Brecha generacional, brecha cognitiva, o las dos juntas y más aún? Revista Mexicana de Investigación Educativa, 11(28), 179-185. https://www. redalyc.org/pdf/140/14002809.pdf

Ramírez, A. (2018). Análisis y tratamiento informático de texto. En Hernández y Hernández, D., Cassany, D. \& López González, R. Prácticas de lectura y escritura en la era digital (pp.102-120). Editorial Brujas.

Reckwitz, A. (2002). Toward a theory of social practices: A development in culturalist Theorizing. European Journal of Social Theory, 5(2), 243-263.

Riquelme, A. \& Quintero, J. (2017). La literacidad, conceptualizaciones y perspectivas: hacia un estado del arte. Revista Reflexiones, 96(2), 93-105.

Rockwell, E. (2009). La experiencia etnográfica: historia y cultura en los procesos educativos. Paidós.

Rodríguez, A. (2005). Lectura e Internet: Dos tecnologías. Investigación Bibliotecológica, 19(38), 11-32. http://dx.doi.org/10.22201/iibi.01873 58xp.2005.38.4059

Romero, A. (2016). Diagnóstico de prácticas de lectura en niños y jóvenes en México y propuesta. A leer/ IBBY México. https://www.senado.gob.mx/ comisiones/biblioteca/docs/diagnostico_practicas_lectura.pdf
Rosas, P., Sánchez, R. \& Lozoya, J. (5-9 de octubre del 2020). Pistas para el desarrollo de prácticas situadas de lectoescritura. Resultados de una encuesta de prácticas y hábitos de lectoescritura en el pregrado [Ponencia virtual]. 1er Congreso de Literacidad para una Cultura Científica. Jalisco, México. https://www.youtube.com/ watch?v=oGsg4aRptqM\&feature=youtu.be

Ruiz-Bejarano, A. (2016). Hacia una etnografía de la lectura escolar. Prácticas y representaciones de la lectura en la escuela. Álabe. Revista de la Red de Universidades Lectoras, 14, 1-21. https://doi. org/10.15645/Alabe2016.14.2

Street, B. (1984). Literacy in theory and practice. Cambridge.

Vargas, A. (2018). Redes sociales, prácticas letradas e identidad(es): el caso de Facebook. Una aproximación al estado del arte. En Hernández y Hernández, D., Cassany, D. \& López González, R. Prácticas de lectura y escritura en la era digital (pp. 193 - 216). Editorial Brujas.

Wolfe, S., \& Flewitt, R. (2010). New technologies, new multimodal literacy practices and young children's metacognitive development. Cambridge Journal of Education, 40(4), 387-399.

Zafra, R. (2017). Lectores y escritores de sí mismos. En F. Cruces (Dir.) ¿Cómo leemos en la sociedad digital? lectores, "booktubers" y prosumidores (pp. 81-102). Ariel | Fundación Telefónica. 